research importer, and that the Dominion's pre-war per capita expenditure of research was far below that of other industrial nations. It is suggested that Canada, through its National Research Council, should maintain in the immediate post-war years a programme of research equal to, or greater than, the present war research effort, which is five times as great as that of the pre-war years. Consideration has been given to a long list of topics suggested as subjects for research in the post-war period, and suitable action indicated. Among many now problems suggested to develop the natural resources of the Dominion or to improve living conditions of the people may be mentioned road research, housing and building research, transport by air, rail, road and water, cold weather and northern latitude problems and the utilization of agricultural crops and products of the forest. Research is recommended on the construction, heating, lighting etc., of small homes, the development of cheap refrigeration units for farm homes, cold-storage locker systems for farms, and farm equipment including plumbing and farmpower units.

It is recognized that the universities must re. main the chief centres for training scientific personnel in special fields and should be the chief centres for pure research, although such research must be fostered to a limited extent in the Council's own laboratories. The chief concern of these laboratories should be research on problems expected to yield results for immediate practical application, and provision should be made for this work to be carried to the stage of pilot-plant operation. Provision for the interchange of research workers between the National Research Council, universities, Government departments, and other research organizations in Canada is strongly recommended, as well as the development of research intelligence and the international exchange of research information. The establishment of liaison officers in London and Washington is noted as a policy which might be profitably extended in the post-war period. The value of such co-operation in war research is specially stressed in this report, which notes that it has been possible to plan research with some understanding of the use likely to be made of the results by the Allied Nations, and also it has enabled Canadian workers to discuss their problems at first hand and to establish close relations with other scientific workers investigating similar problems.

\section{New Map of the Moon}

Mr. H. Peroy Wrukrns is a well-known observer of lunar features and has done a considerable amount of very useful work in this particular branch of astronomy. In 1932 he published his 200 in. map of the moon, and now he has brought out a new map which is $25 \mathrm{ft}$. in diameter and by far the largest map of the moon in existence. It is contained in 107 sheets, each 22 in. by 30 in., bound in three volumes and deposited in the Library of the British Astronomical Association, Burlington House, Piccadilly, London. This map was commenced in 1932 and displays a great amount of care and attention to details-the number of ring-like objects is about 60,000 , and many other objects are noted. The number of named objects is 700 , including 28 new names; all the names contained in "Who's Who in the Moon" have been included. A large number of new clefts have been inserted as a result of the author's own observations since 1932. Although positions are mainly based on Saunder's list, Mr. Wilkins has made many new measurements with a micrometer, especially of objects near the limb. The large scale-300 in. diameter-is just sufficient to show clearly minute details in the more crowded regions. It is proposed to publish the map on the reduced scale of $100 \mathrm{in}$. to the moon's diameter, in 25 sections, each 20 in. square, and for the purpose of this reproduction the entire map was re-drawn to this scale, one-third of the diameter of the original sheets. Selenographers will find this map of the moon invaluable for their work.

\section{Trapping Fleas}

A. H. Al-HussainI, of the Department of Zoology, Farouk I University, Alexandria, has described, in a communication to the Editors, a simple trap for catching fleas. A plate of 7-8 $\mathrm{mm}$. depth and not less than $20 \mathrm{~cm}$. diameter is filled with soapy water ; a one candle-power petroleum lamp, with a flat supporting base, is put in the middle of the plate. Fleas being thermotropic and thus attracted by the heat of the lamp, they jump towards it and fall into the plate, where they are rapidly 'drowned' in the soapy water. The great majority of fleas caught by this trap are females. Two possible interpretations to this high percentage of females can be offered: (1) the female seeks a hide to lay its eggs, and the hotter the hide the more favourable it is for hatching the eggs ; (2) the numbers may indicate the natural ratio between the females and males in the human flea (Pulex irritans), which would thus be approximately $25: 1$.

\section{The Venereal Diseases}

A RECENT pamphlet, "People Who Live in Glass Houses", by a "V.D. Orderly" (Harold Thomas) (London : The Central Couneil for Health Education, 1945. Pp. 80. 9d.), gives an accurate account of the common venereal diseases. One would guess that the material was originally used by the author for lectures to young men. As such, and delivered in a breezy 'man to man' style, it was no doubt successful with a certain type of audience; but Mr. Thomas has not achieved the task of translating his message into writing. The lay reader, who is able to accept the style, may not be inspired by the length. There is just too much to be read at a sitting and some of the information, good though it is, is redundant. An orderly in a venereal diseases clinic has a position of great responsibility and is often the friend and counsellor of the patients. Mr. Thomas has obviously made the most of his opportunities for observation of the conduct and mode of life of his patients. We can praise his sincerity and intentions but not his book.

\section{University of Leeds}

AT a meeting of the Council of the University of Leeds on October 17, Dr. W. T. Astbury, reader in textile physics in the University, was appointed to the newly instituted chair of biomolecular structure which has been established for Dr. Astbury personally as a tribute to his merit as an investigator. The title of emeritus professor was conferred upon Dr. R. W. Whytlaw-Gray, who recently retired from the chair of chemistry. Mr. Wilfred Prest, acting professor in the University of Melbourne, was appointed visiting lecturer in the Department of Economics and Commerce during the second and third terms of the present session. 